\section{"Stepping out of the ordinary": exploring cross-cultural challenges of expatriates in the Kingdom of Saudi Arabia}

\section{Cross-cultural challenges of expatriates

\author{
Oscar Dousin
}

Faculty of Business, Economics and Accountancy, Universiti Malaysia Sabah, Kota Kinabalu, Malaysia, and

Rini Suryati Sulong

Labuan Faculty of International Finance, University Malaysia Sabah - Labuan

International Campus, Labuan, Malaysia
Received 7 January 2021 Revised 24 February 2021 Accepted 24 February 2021

\begin{abstract}
Purpose - In the study of expatriation and expatriate adaptation, there are limited studies that focus on issues faced by expatriates working in foreign countries with very distinct cultures. This study aims to explore this idea through the experiences of western expatriates working in the Kingdom of Saudi Arabia (KSA). Two research questions were posed to examine the cross-cultural issues and challenges faced by expatriates in the KSA, as well as the role of cross-cultural training in expatriate adjustment.

Design/methodology/approach - The study was guided by an interpretivism paradigm through a qualitative method by using a semi-structured in-depth interview approach. Interviews were conducted among 12 expatriates from the USA and UK who are currently working in KSA.

Findings - A coding technique and theoretical thematic analysis was conducted to analyze the data. The results of this study highlighted three key themes that had a considerable influence on expatriates' adjustment, in particular: culture shock, lack of pre-departure training and the demand for an extensive cross-cultural training.

Research limitations/implications - It is acknowledged that the existence of sub-cultures within the KSA would expose the respondents to varying cultural values within the community. Thus, future studies within a similar context should consider the influence of intra-cultural variations.

Originality/value - The findings of the study emphasized on the importance understanding the cultural gap between home and host country and the individual cultural awareness of the expatriate. It calls attention to the need for a tailored and extensive pre-departure, cross-cultural training and a collaborative effort between employees' and managers to improve expatriates' motivation and retention.
\end{abstract}

Keywords Expatriate, Cross-cultural, Training, Cultural awareness,

Kingdom of Saudi Arabia (KSA)

Paper type Research paper

(C) Oscar Dousin and Rini Suryati Sulong. Published in Rajagiri Management Journal. Published by Emerald Publishing Limited. This article is published under the Creative Commons Attribution (CC BY 4.0) licence. Anyone may reproduce, distribute, translate and create derivative works of this article (for both commercial and non-commercial purposes), subject to full attribution to the original publication and authors. The full terms of this licence may be seen at http://creativecommons.org/licences/by/4.0/legalcode

The authors appreciate expatriates from Taif, Kingdom of Saudi Arabia who have participated in this study.

Funding: The author(s) received no financial support for the research, authorship, and/or publication of this article.

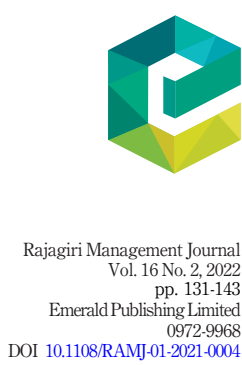


RAMJ

16,2

\section{Introduction}

Globalization encourages the arrival of expatriates into most countries to meet the demands for skilled and professional employees. Globalization of production and marketing creates integrated worldwide operations that require most companies to transfer their employees to foreign countries and preserve the standards of firms' goods and services abroad (Bartol and Martin, 1998; Dowling et al., 2017; Tahir and Ismail, 2007). Employees who are sent abroad on international assignments, which entails that they are working and living in a foreign country for a specific period of time, are referred to as an "organizational expatriate" (Dowling et al., 2017; Selmer and Lauring, 2012). However, due to the complexity and unique nature of most international assignments, expatriation also comes in various forms. There is also a growing number of "self-initiated expatriates" in the realm of international business. These expatriates can be defined as people who decided to migrate to a foreign country for work or were hired on a contractual basis, funding their own relocation as part of their personal agendas (Froese and Peltokorpi, 2011; Howe-Walsh and Schyns, 2010; Selmer and Lauring, 2012).

Living and working in a new physical and cultural environment can be challenging for most expatriates. Besides having to adjust their whole lifestyle, they are also faced with the challenges of making their transition into the new work surroundings as smooth, effective and efficient as possible (Ward and Rana-Deuba, 2000; Zakaria, 2000; Froese and Peltokorpi, 2011; Tahir and Ismail, 2007). The challenges of expatriates' adjustment include: "workrelated norms, isolation, housing, schooling, differences in healthcare, language, customs, gender-roles, cost-of-living, cuisines and homesickness" (Goby et al., 2002, p. 75). An expatriate turnover or expatriation failure is defined as "the premature return of an expatriate (that is, a return home before the period of assignment is completed)" (Dowling et al., 2017, p. 126). As the cost of expatriate turnover is significant due to the potential loss of market share, relocation and training expenses, drop of productivity and morale of the local employees (Dowling et al., 2017), the issue of cross-cultural adaptation as well as understanding the expatriates' needs and training needs are critical to improve their retention.

Both scholars and human resource (HR) practitioners agreed that pre-departure and cross-cultural training could improve expatriates' ability to adapt and perform in foreign assignments (Forster, 2000; Waxin and Panaccio, 2005). Nevertheless, the cross-cultural training provided by most organizations has been found to be inadequate, imperfect or simply missing (Brewster, 1995; Waxin et al., 1997; Selmer, 2000; Waxin and Panaccio, 2005; Tahir and Ismail, 2007). Although numerous studies have been conducted to investigate the effectiveness of cross-cultural training to improve expatriates' adaptation and job performance, there is still only a small number of studies that explore this issue among western expatriates' adjustment to the Kingdom of Saudi Arabia (KSA). Therefore, this study aims to explore the issue of cross-cultural issues and coping strategies among expatriates in the KSA by investigating two research questions (RQs):

$R Q 1$. What cross-cultural adjustment issues do expatriates' experience while working in the KSA?

RQ2. How can training be designed and developed to improve cross-cultural adjustment among expatriates in the KSA?

Our study makes two significant contributions. With regard to the theoretical contribution, it enhances our understanding on the influence of national culture and customs to expatriates' adaptability as well as the need for an extensive training program catered to 
unique working conditions (Shannon-Baker, 2015; Tahir and Ismail, 2007; Kaufmann et al., 2014). Consistent with the rationale of cross-cultural management theory (Bartol and Martin, 1998), this study highlights challenges faced by western expatriates exposed to the unique customs and culture of working directly with Saudis, noting in particular that the lack of pre-departure training will lead to adjustment difficulties and "culture shock" among expatriates. Then, the study provides practical contributions by suggesting an extensive cross-cultural training as a prerequisite to improve expatriate retention in the KSA. We argue that expatriate-perceived cultural familiarity could lead to quicker adjustment because they will develop an expectation on the KSA culture and customs (Selmer and Shiu, 1999).

\section{Literature review}

\section{Cross-cultural issues among expatriates}

Bartol and Martin's (1998) cross-cultural management theory was used to guide this study. This theory refers to a process in which management takes into account cultural differences and a person's ability to adapt with different cultures. In a study by Tahir and Ismail (2007), the authors mentioned that culture shapes the mentality of individuals in a society, which guides their mindsets, manage their lives and used to make and prioritize decisions. The study further suggested that the concepts of self-awareness and cultural awareness are closely linked together; "one has to go beyond the meaning of culture itself in order to have a better awareness of how culture influences their lives" (p. 76) (Tahir and Ismail, 2007).

The KSA is the birthplace of Islam, home of the two holiest shrines in the cities of Mecca and Medina, as well as being known as a notable trade hub (Visit Saudi, 2020; 2020 Index of Economic Freedom, 2020). In the 2020 economic index, Saudi Arabia's current gross domestic product (GDP) is US\$1.9tn with its economic freedom score is $62.4 \%$ : ranked 9 th among 14 countries in the Middle East and North Africa region (2020 Index of Economic Freedom, 2020). The KSA economy is almost completely based on oil, with GDP growth being closely associated to actual oil growth, but the government is continuing its effort to diversity the economy away from dependence on oil (Nordea, 2020; 2020 Index of Economic Freedom, 2020). The KSA is a monarchy, ruled by King Salman bin Abdulaziz Al Saud, with a population of 33.2 million (2020 Index of Economic Freedom, 2020). The official language of Saudi Arabia is modern-standard Arabic, used in all businesses and public communications, whereas English is considered as the informal second language of business, which is spoken by a majority of its citizens (Visit Saudi, 2020). Nevertheless, outside the major cities, modern-standard Arabic and "gulf" Arabic (a mixture of regional dialects of Arabic) are predominantly spoken by the local populace. The culture and public customs of the country is formed by their cultural heritage and the Islamic religion, which guides all aspects of life (public and private) while upholding the values of respecting others, protection of privacy and dignity in public.

This study explored the cross-cultural issues and challenges, as well as the coping strategies among western expatriates working in the KSA. According to Hofstede (2019), in comparison to the USA and the UK, the KSA scores high on power distance, low on individualism, moderate in masculinity, high on uncertainty avoidance and moderate on long-term orientation and indulgence. A high score in power distance indicates that the peoples of Saudi Arabia (or Saudis) are more accepting of a hierarchical order in which everyone has a position and which needs no added reasoning. In an organization, hierarchy reflects inherent differences, acceptance on centralization where employees expect and prepare to be instructed on what to do and the ideal manager is a compassionate autocrat. In addition, Saudis are also considered as a collectivistic society, wherein they appreciate
Cross-cultural challenges of expatriates 
RAMJ

16,2

long-term commitment to the member "group" where everyone is expected to take responsibility for members of their group, and loyalty is a priority. Although scoring moderate as a masculine society, managers in Saudi Arabia are expected to be assertive and decisive, putting emphasis on equity, performance and competition. It was also found that in the Arab culture, conflicts can be resolved by fighting them out (Hofstede, 2019). Thus, Saudi Arabia could be perceived as a challenging environment of work for people coming from opposite cultural dimensions, such as the Americans and British, because of the different norms and attitudes influenced by the dominant culture in society. For an example, in American companies, hierarchy is established for conveniences, managers are available and rely on their subordinates and teams for their expertise. Both managers and subordinates expect to be referred to, information sharing is a common practice and where informal, direct and participative communication is expected (Hofstede, 2019).

\section{Expatriates success factors}

In the field of expatriation research, Black and Gregersen (1999) revealed that 10 and 20\% of overall managers from the USA, working as expatriates, returned home before completing the period of assignment due to job dissatisfaction or difficulties to adjust with the culture in a host country. Interestingly, their study revealed that one-third of expatriates who continue working were found to not perform up to the expectations of the companies, and one-fourth of those who did complete the assignment, left the organization, frequently to join a competitor, within one year after repatriation. Even though the challenges of international assignments are unique to each area posting, it can undoubtedly affect an expatriate's ability to perform the job effectively. Other than physical location-related factors, the ability for expatriates to adjust and perform successfully also depends highly on cross-cultural factors (Froese and Peltokorpi, 2011).

Furthermore, Black and Gregersen (1999) suggested several important employees' traits to ensure the expatriation assignment will be a success, including:

- a drive to communicate, enthusiastic and extrovert;

- broad-based sociability to the local communities;

- cultural flexibility;

- cosmopolitan mindset orientation, to be able to understand that different cultural norms have value and meaning to those who practice them; and

- collaborative negotiation style.

Moreover, Selmer (2000) mentioned that the expatriates' expectations about the new culture and the attributions they make about what transpires in the new environment will significantly influence their adjustment in this overseas assignment. A study by Selmer and Shiu (1999) revealed that perceived cultural closeness seemed to develop expectations of effortless and swift adjustment, which could, if it was not achieved, could lead to expatriation failure. In addition, Goby et al. (2002) proposed that knowledge of the host country environment, communication skills, educational backgrounds, family adaptability, flexibility, patience and adaptability are crucial in ensuring success of expatriate assignments. From an organizational perspective, Goby et al. (2002) further proposed that language training, job-specific training and cross-cultural training were important for Singaporean expatriates to work in China.

Expatriates are required to have a certain type of skillset to survive in a foreign environment. Among the critical factors that determine the potential success or failure of expatriation are related to the acquired skills of the expatriate, be they gained through 
experience or the training provided by the relevant organizations. In regard to training, Kealey and Protheroe (1996) mentioned that most organizations did not provide adequate pre-departure training and briefing for expatriates, rather selecting them solely based on technical competence and experience. Most organizations make less effort in conducting cross-cultural training because of the short duration of expatriate overseas assignments (Osman-Gani, 2000; Goby et al., 2002). At a macro-organization level, Kang and Shen (2018) recommended that host country personality, perceived compensation gap between expatriates and host countries, task cohesiveness, interpersonal affect and relationships, host country previous contact with expatriates and expatriate justice will directly and indirectly influences expatriate adjustment and performance.

Previous studies have emphasized the role of culture and cross-cultural training as important determinants of expatriate performance (Froese and Peltokorpi, 2011; Tahir and Ismail, 2007; Waxin and Panaccio, 2005). In addition to that, Waxin and Panaccio (2005) further revealed that cross-cultural training helps to facilitate expatriate adjustment, which must be conducted according to the "hardness" or level of novelty of the host country's culture. The training should be customized to the cultural gap between their home and host country as well as the nature and duration of the assignment and position. Moreover, Goby et al.'s (2002) study also revealed the importance of language and sensitivity training, field experiences, cultural assimilator and area study program as important training techniques to ensure expatriates could effectively perform in the host country. Hence, it can be argued that effective training for expatriates should include cultural factors that would provide the knowledge and skills pertinent for the expatriate to effectively interact with the local society as well as work colleagues.

\section{Methodology}

This study was guided by an interpretivist inquiry paradigm, by adopting in-depth semistructured interviews to explore the experiences of the USA and UK expatriates working in the KSA. As suggested by Easterby-Smith et al. (2002), interviews are a two-way communication and is a powerful mean to explore meaning, acquire historical evidence and to learn intricacy of issues. In addition, to improve reliability, we conducted interviews with participants who have different cultural backgrounds and work experiences (Miles and Huberman, 1994). A purposive sample of 12 participants from the city of Taif, KSA, were interviewed in 2018-2019. Pseudonyms were being used to give anonymity to participants to protect their confidentiality. The study selection criteria included country of origin, years of experience as expatriate, years of attachment and job scope. Participation to the study was voluntary, and consent was obtained for the purpose of confidentiality and anonymity. All interviews were conducted online, through communication applications such as Skype, Facebook and WhatsApp. Interview questions revolve around the key themes of the study, including what does expatriation means to the participant? How about their experiences working in the KSA? What are the key factors that impact their motivation and retention? These questions were not precisely followed because we expected that new questions would arise during interview sessions (Myers, 2019) to ensure participants could share their personal circumstances and experiences. The duration of the interviews ran between 30 and $60 \mathrm{~min}$ per session and were audio recorded and transcribed for data coding. Table 1 shows the participants' profile.

All interview data was analyzed using coding techniques (Corbin and Strauss, 2008), and theoretical thematic analysis (Braun and Clarke, 2006) was implemented to conceptualize the occurrence of the study because this method will identify and analyze patterns of meanings in a data set, as well as illustrates which themes are important (Braun and Clarke, 2006;
Cross-cultural challenges of expatriates

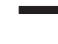




\section{RAMJ \\ 16,2}

Participants profile $\quad$ Note: $N=12$

Years of attachment Years of experience

No. Participants in the current job Marital status as expatriates Gender Age range

01. Grant Less than 1 year Married 11 years 6 months Male 25-35 years old

02. Sheldon Less than 1 year Married Not stated

03. Wayne More than 5 years

04. Rob 1-3 years

Married

Married

6 years 6 months

Not stated

Less than 1 year

Married

06. Jason

3-5 years

Married

4 years 6 months

Not stated

Less than 1 year

08. Mike

09. Ash

More than 5 years

Married

23 years

Married 17 years

$1-3$ years

More than 5 years

Single

12 years

5 years

1-3 years

Single

Single

12. Trevor More than 5 years Married 16 years
Male 25-35 years old

Male $\quad 45-55$ years old

Male 25-35 years old

Male 25-35 years old

Male 45-55 years old

Male 45-55 years old

Male Over 56 years old

Male Over 56 years old

Male 45-55 years old

Male 35-55 years old $\begin{array}{ll}\text { Male } & 35-55 \text { years old } \\ \text { Male } & 45-55 \text { years old }\end{array}$

Daly et al., 1997; Joffe, 2012). Figure 1 illustrates excerpts of how the coding process evolved from the first-order code to the aggregate dimensions that explain the participants' experiences of their expatriation (Gioia et al., 2012). First-order codes are produced by analyzing the participants statements and actions by commonalities. It was then followed by the second-order theme, focused on the conceptual constructs, that was aligned and coherent with RQs. The aggregate dimensions revealed that national culture and customs influence expatriate adjustment and the need for an extensive cross-cultural training to ensure successful expatriation.

\section{Findings and discussion}

Based on the analysis, three major themes were found in relation to cross-cultural adjustment issues experienced by the participants of the study.

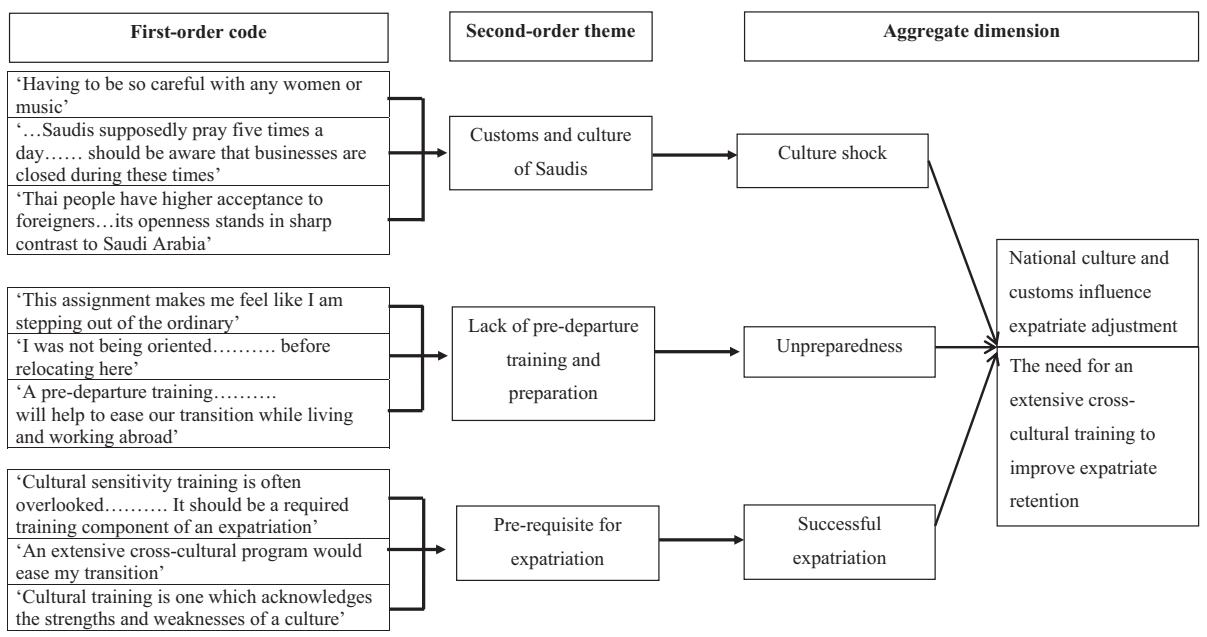

Figure 1.

Qualitative data structure 


\section{Theme 1: "culture shock" toward the customs and culture of Saudis}

The majority of participants stated that they faced culture shock at the beginning of the work assignment. For all of the expatriates interviewed, working in the KSA gave them a new experience, as the people, culture and environment of the country were very different than that of their home countries.

Jason, an American who had no experience working in the KSA or any Middle East country, spoke about his culture shock experience:

Cross-cultural challenges of expatriates

Since Saudis supposedly pray five times a day, an expat or foreigner should be aware that businesses are closed during these times, which can make life inconvenient at times (Jason).

Mike, also an American who did have experience working as an expatriate in Thailand for 15 years, seconded Jason in this view about culture shock while working in the KSA. Mike shared:

I feel that when I was working in Thailand for 15 years, the Thai people have higher acceptance to foreigners, its openness stands in sharp contrast to Saudi Arabia (Mike).

In addition, the expatriates noted that the majority of Saudis are Muslims, and there are several restrictions in the Islamic religion, which guides their living practices and norms. Therefore, expatriates should be thoughtful about their actions and words in the workplace and in the general public. Woody, an American, spoke about this issue in relation to performing his job:

Having to be so careful with any women or music or other frowned upon elements in videos or listening that I would do in conducting a classroom training. I am not able to play songs during my session because it might offend some strict Muslim colleagues or students [or] I will get reprimanded by military [management] (Woody).

Moreover, several participants also felt surprised with the unfamiliar customs and dishes of the Saudis. Sheldon, a British expatriate who works in Saudi for less than a year shared his experience about dining with Saudis:

I consider myself as an adventurous 'eater', but during a gathering for dinner with my neighbor, I was shocked when I was offered sheep's tongue, which is considered a rare Saudi delicacy. I have never eaten it before, but I don't want to offend the host, so I give it a try. I consider this as a cultural exchange (Sheldon).

The culture "shock" or challenges in a cross-cultural encounter is defined as the responses to "the loss of perceptual reinforcements from one's own culture, to new cultural stimuli which have little or no meaning, and to the misunderstanding of new and diverse experiences" (Adler, 1975, p. 13). Culture shock is an outcome of a gap in one's prospects about or the distance between the cultures involved (Pitts, 2009; Mumford, 1998; Searle and Ward, 1990; Shannon-Baker, 2015).

What can be discerned from the experiences of the western expatriates working in the KSA is that stark differences in culture can affect perception and actions of expatriates. For most of the participants, they had none or very minimal experience working in Middle East countries, particularly in Saudi Arabia, and lacked in-depth knowledge about the customs, attitudes and culture of the Saudis. Therefore, these cultural clashes will eventually happen, in particular misunderstandings about the closure of business during prayer times and other religious-related practices according to the Islamic practice effects on overall work and personal life.

\section{Theme 2: "unpreparedness": lack of pre-departure training and preparation}

Almost all participants agreed that they were unprepared to move and work in the KSA due to the lack of pre-departure training and preparations made by the home country 
organization. A well-developed and constructive pre-departure training will assist employees to anticipate and plan for challenges they may experience when they move to the KSA. This issue was highlighted by Rob, an American who has been working in the KSA for less than three years:

I think many people confuse culture shock with the lack of familiarity. It's the feeling like everything is new and somewhat frustrating [...] This assignment makes me feel like I am stepping out of the ordinary (Rob).

Another expatriate, Sheldon, a British, also talked about the lack of preparation given by their home country manager. Sheldon stated that:

I was not being oriented about the 'real' customs and the Saudi cultures before relocating here.

For an example, a basic local language training would help since I don't speak and understand Arabic at all (Sheldon).

Meanwhile, Jason spoke about how to design an effective pre-departure training and preparation, which could help expatriates to better integrate with their new work environment. He believed that it could help to alleviate the time needed to adapt with the new working and living environment:

A pre-departure training should be a collaborative effort between myself and my employer. From my part, I need to do some research about the culture, history of the country and the specific area in which I will be living and working. Expats need to be aware that not all culture learn the same; therefore, it is imperative that I do my research. Now, my employer [home-country organization] should conduct and funds training such as cultural sensitivity training, language training besides being clear and transparent about expectations and arising challenges. This will help to ease our [expatriates] transition while living and working abroad (Jason).

Mark, an American who has worked as an expatriate for more than ten years cumulatively in South Korea, Turkey and currently in Saudi Arabia, highlighted the important elements of a pre-departure training:

Any pre-departure training should include the question words and 1-10 in the country's language, outline of the culture and pitfall list from people that actually lived there. These elements are practical and helpful to all foreigners (Mark).

The findings revealed that an extensive and effective pre-departure training is critical to improves expatriates' transitions and performance in the host country organization. This is supported by past research, such as by Tahir and Ismail (2007), that found that "there is a need for a structured cross-cultural training program [for expats], since the expatriates will find it useful" in understanding the cultural aspects of the country in which they are residing (p. 90). In another study, Allianz (2018) highlighted the benefits of pre-departures training, which consist of:

- clear understanding of role: pre-departure training should be transparent in communicating the primary goals of the assignment so that employees could easily meet these expectations;

- better integration: help employees to develop emotional flexibility to accept and respect cultural differences;

- improved language skills by providing host-country's basics language training; and

- improves family well-being, by the inclusion of expatriates families into the predeparture training. 

Issues related to cross-cultural challenges were highlighted by all participants of the study. This indicates that the expatriates studied felt that it was crucial for organizations to conduct an extensive cross-cultural training for their expatriates before moving for work in the Middle East. Trevor, a British citizen, spoke about the needs for a cross-cultural sensitivity training:

Cross-cultural
challenges of
expatriates

Cultural sensitivity training is often overlooked by most organizations, including mine. It should be a required training component of an expatriation, especially to the Middle East (Trevor).

In addition to this view, other participants further highlighted the importance of crosscultural training for long-term expatriation assignments. Duncan stated that:

An extensive cross-cultural program would ease my transition here. This training program is critical and should be made mandatory for a long-term overseas assignment, since we are not only working solely but we are living in a community here. That is why it is important for us to have an in-depth understanding about their culture, so that we don't make silly mistakes unintentionally (Duncan).

This view was also supported by Ash, who had been working in the KSA for almost three years, besides having 12 years' experience working in Japan. He stated that:

The most important cultural training is one which acknowledges the strengths and weaknesses of a culture. Most of the ones I've seen are far too sugar-coated. Political correctness seriously handicaps honest discussion (Ash).

Moreover, due to the stark differences found between the expatriates' culture background and that of the Saudis, there exist a need to develop a cross-cultural training program tailored to the Saudi culture. A "one-size-fits-all” approach might not be effective because there is a huge difference between the Saudi and western cultures. For example, Rob, a firsttime expat, spoke about how to design an extensive cross-cultural training for international assignments to the KSA.

All companies should be able to tailor their training to fit with the culture and the specific organization. In my case, the training should include: primitive language training, an intro to driving in Saudi Arabia, understanding how business works, how to communicate and function with supervisors that constantly change their minds, how to approach your colleagues and the dos and don'ts of living here (Rob).

Generally, based on these interviews, expatriates demanded an extensive cross-cultural training as a prerequisite to their overseas assignment. This initiative could improve their motivation and retention to work in an environment with distinctive cultural differences. In addition, the study also supports the findings by Kaufmann et al. (2014), which suggested that a tailored-based cross-cultural training is required for individual employees to become interculturally competent. A "one-size-fits-all” approach is seen as not effective, as various features of the training need to be tailored to fit the culture and the needs of the particular organization. In addition, the findings of this study are also consistent with the research done by Ko and Yang (2011), which revealed that training on the local language helps to facilitates expatriates' cross-cultural adjustment by building their ability to develop harmonious relationships with the host countries' employees, resulting in an improvement of job performance. Hence, expatriates' knowledge and understanding of the local business norms and customs are also crucial to ensure the success of their overseas assignment (Ko and Yang, 2011; Goby et al., 2002). Furthermore, the training could improve expatriates 
RAMJ

16,2

career adaptability, which is a key element to influence job performance and adjustment (Jannesari and Sullivan, 2019).

\section{Theoretical implications}

The findings of this study contributes to expanding the discussion on the influence of host country environment - particularly that of the KSA - on expatriate adjustment and training requirements. The study also emphasized on the importance of individual cultural awareness with adequate support from management to mitigate issues related to expatriate adaptation, retention and motivation at work, which eventually could avoid expatriate failure. It ultimately contributes to expanding the cross-cultural management theory (Bartol and Martin, 1998) to better understand the cultural differences and ability to adapt with the Saudi culture among western expatriates. In line with this, it supports the idea that an establishment of a strong support system from spouse, friends, colleagues and managers could also improve expatriate's retention and general adjustment in the new working environment (Tahir and Ismail, 2007; Kraimer et al., 2001).

Furthermore, the study confirms the relevance of the cross-cultural training model by Mendenhall et al. (1987) as practical and beneficial to be implemented before sending any employees for overseas assignment. As all participants of the study are in a long-term assignment (1-3 years); therefore, a 1-2 months of extensive cross-cultural training in an assessment center should be implemented by including field experiments, simulations, sensitivity training and extensive language training (Mendenhall et al., 1987). The conclusions derived from the personal experiences and adjustment issues of the expatriates studied enhances our understanding on the influence of national culture and customs to expatriates' adaptability, as well as suggests the need for a more inclusive training program that can make use of expatriate knowledge. This initiative is perceived as career support and supportive organizational practices, and it is important in retaining expatriates in the host countries (Goštautaite et al., 2019; Cao et al., 2014; Chen and Shaffer, 2017).

\section{Limitations and directions for future research}

The study acknowledged several limitations. The interviews were conducted among expatriates working in only one city in the KSA, which could have a different cultural environment with other cities in the Kingdom. The context of this study assumes the homogeneity of cultural values and norms of the host country such that of the KSA, which has a strong cultural base founded on a long-established monarchy, traditions and religious belief - particularly in the city where the respondents are working. Nevertheless, it is acknowledged that the existence of sub-cultures can mean that cultural values can vary considerably even within a homogenous community and more so within a state. Therefore, future studies to be conducted within a similar context should consider the influence of intra-cultural variations. An expansion of the study could also be undertaken on a regional level to include other countries in the Middle East with shared cultural identity, which could better reflect and generalize this issue.

Furthermore, the study could be extended and quantified through a quantitative or mixed-methods research approach to further examine and understand the cross-cultural issues of expatriates in this region. Although a qualitative research typically involves a small number of participants, there is a limitation to its representative nature of the experiences of other expatriates working in the KSA. Hence, the findings in the present study should be further examined using a more diverse and larger sample size. 


\section{Conclusion}

The findings of the study emphasized three key factors to influence the experience of expatriates' performance, motivation and retention in the KSA. Specifically, most expatriates experienced culture shock at the beginning of their career in the KSA due to the distinctive cultural differences with almost no experience of working in the Middle East region. Surprisingly, several organizations did not conduct a proper pre-departure training and extensive cross-cultural training before sending their employees to work in this foreign environment. This result is consistent with studies by Kealey and Protheroe (1996), OsmanGani (2000) and Goby et al. (2002), which revealed that most organizations select their expatriates solely based on technical competence and experience besides their perception about the short duration of their overseas assignment; thus, cross-cultural training is not required. Moreover, the study suggested a tailored and extensive cross-cultural training should be given to expatriates, which emphasized on the uniqueness of the Saudi culture, basic local language and understanding the norms and practices of the host-country organization. The development of the training program should be a collaborative effort between the employees and the organizations. Individual employees should also have selfinitiative to learn about the culture, business norms, history and living conditions of their overseas working areas.

\section{References}

2020 Index of Economic Freedom (2020), "Saudi Arabia”, available at: www.heritage.org/index/ country/saudiarabia

Adler, P. (1975), "The transitional experience: an alternative view of culture shock", Journal of Humanistic Psychology, Vol. 15, pp. 13-23.

Allianz (2018), "5 Benefits of pre-departure training for expatriates”, available at: www.allianzcare.com/ en/employers/employer-blogs/2018/06/expat-training.html

Bartol, K.M. and Martin, D.C. (1998), Management: International Edition.

Black, J.S. and Gregersen, H. (1999), The Right Way to Manage Expatriates, Harvard Business Review, March-April 1999 issue.

Braun, V. and Clarke, V. (2006), "Using thematic analysis in psychology", Qualitative Research in Psychology, Vol. 3 No. 2, pp. 77-101.

Brewster, C. (1995), "Effective expatriate training", Expatriate Management: New Ideas for International Business, pp. 57-71.

Cao, L., Hirschi, A. and Deller, J. (2014), "Perceived organizational and intention to stay in host countries among self-initiated expatriates: the role of career satisfaction and networks", The International Journal of Human Resource Management, Vol. 25 No. 14, pp. 2013-2032.

Chen, Y.-P. and Shaffer, M.A. (2017), "The influences of perceived organizational support and motivation on self-initiated expatriates' organizational and community embeddedness", Journal of World Business, Vol. 52 No. 2, pp. 197-208.

Corbin, J. and Strauss, A. (2008), Basics of Qualitative Research: Techniques and Procedures for Developing Grounded Theory, 3rd ed., Sage, Thousand Oaks, CA.

Daly, J., Kellehear, A. and Gliksman, M. (1997), The Public Health Researcher: A Methodological Approach, Oxford University Press, Melbourne.

Dowling, P.J., Festing, M. and Engle, A. (2017), International Human Resource Management, Cengage Learning, London.

Easterby-Smith, M., Thorpe, R. and Lowe, A. (2002), Management Research: An Introduction, 2nd ed., Sage, London.

\section{Cross-cultural challenges of expatriates}


RAMJ

16,2

Forster, N. (2000), "Expatriates and the impact of cross-cultural training", Human Resource Management Journal, Vol. 10 No. 3, pp. 63-78.

Froese, F.J. and Peltokorpi, V. (2011), "Cultural distance and expatriate job satisfaction”, International Journal of Intercultural Relations, Vol. 35 No. 1, pp. 49-60.

Gioia, D.A., Corley, K.G. and Hamilton, A.L. (2012), "Seeking qualitative rigor in inductive research: notes on the Gioia methodology", Organizational Research Methods, Vol. 16 No. 1, pp. $15-31$.

Goby, V.P., Ahmed, Z.U., Annavarjula, M., Ibrahim, D.N. and Osman-Gani, A. (2002), "Determinants of expatriate success: an empirical study of Singaporean expatriates in the people's republic of China”, Journal of Transnational Management Development, Vol. 7 No. 4, pp. 73-88.

Goštautaite, B., Bučiūnienè, I., Mayrhofer, W., Bareikis, K. and Bertašiūtè, E. (2019), "Using embeddedness theory to explain self-initiated expatriation intention of entry-level job applicants", Career Development International, Vol. 25 No. 2, pp. 69-89.

Hofstede, G. (2019), “What about Saudi Arabia?”, itim, International Helsinki, Finland, available at: www.hofstede-insights.com/country-comparison/saudi-arabia/

Howe-Walsh, L. and Schyns, B. (2010), "Self-initiated expatriation: implications for HRM", The International Journal of Human Resource Management, Vol. 21 No. 2, pp. 260-273.

Jannesari, M. and Sullivan, S.E. (2019), "Career adaptability and the success of self-initiated expatriates in China”, Career Development International, Vol. 24 No. 4, pp. 331-349.

Joffe, H. (2012), Chapter 15: Thematic Analysis in Qualitative Research Methods in Mental Health and Psychotherapy: A Guide for Students and Practitioners, Harper, D. and Thompson, A. (Eds), Wiley-Blackwell, Chichester, 209-223.

Kang, H. and Shen, J. (2018), "Antecedents and consequences of host-country nationals' attitudes and behaviors toward expatriates: what we do and do not know", Human Resource Management Review, Vol. 28 No. 2, pp. 164-175.

Kaufmann, H.R., Englezou, M. and Garcia-Gallego, A. (2014), "Tailoring cross-cultural competence training", Thunderbird International Business Review, Vol. 56 No. 1, pp. 27-42.

Kealey, D.J. and Protheroe, D.R. (1996), "The effectiveness of cross-cultural training for expatriates: an assessment of the literature on the issue", International Journal of Intercultural Relations, Vol. 20 No. 2, pp. 141-165.

Ko, H.C. and Yang, M.L. (2011), "The effects of cross-cultural training on expatriate assignments", Intercultural Communication Studies, Vol. 20 No. 1, pp. 158-174.

Kraimer, M.L., Wayne, S.J. and Jaworski, R.A.A. (2001), "Sources of support and expatriate performance: the mediating role of expatriate adjustment", Personnel Psychology, Vol. 54 No. 1, pp. 71-99.

Mendenhall, M.E., Dunbar, E. and Oddou, G.R. (1987), "Expatriate selection, training and careerpathing: a review and critique", Human Resource Management, Vol. 26 No. 3, pp. 31-345.

Miles, M.B. and Huberman, A.M. (1994), An Expanded Sourcebook: Qualitative Data Analysis, 2nd ed., SAGE Publications, Thousand Oaks.

Mumford, D.B. (1998), "The measurement of culture shock", Social Psychiatry and Psychiatric Epidemiology, Vol. 33 No. 4, pp. 149-154, doi: 10.1007/s001270050037.

Myers, M.D. (2019), Qualitative Research in Business and Management, Sage Publications, Thousand Oaks.

Nordea (2020), "Country profile Saudi Arabia: the economic context of Saudi Arabia", available at: www.nordeatrade.com/en/explore-new-market/saudi-arabia/economical-context

Osman-Gani, A.M. (2000), "Developing expatriates for the Asia-pacific region: a comparative analysis of multinational enterprise managers from five countries across three continents", Human Resource Development Quarterly, Vol. 11 No. 3, pp. 213-235.

Pitts, M.J. (2009), "Identity and the role of expectations, stress, and talk in short-term student sojourner adjustment: an application of the integrative theory of communication and cross-cultural 
adaptation”, International Journal of Intercultural Relations, Vol. 33 No. 6, pp. 450-462, doi: 10.1016/j.ijintrel.2009.07.002

Searle, W. and Ward, C. (1990), "The prediction of psychological and sociocultural adjustment during cross-cultural transitions", International Journal of Intercultural Relations, Vol. 14 No. 4, pp. 449-464, doi: 10.1016/0147-1767(90)90030-Z.

Selmer, J. (2000), "A quantitative needs assessment technique for cross-cultural work adjustment training”, Human Resource Development Quarterly, Vol. 11 No. 3, pp. 269-281.

Selmer, J. and Lauring, J. (2012), "Reasons to expatriate and work outcomes of self-initiated expatriates", Personnel Review, Vol. 41 No. 5, pp. 665-684.

Selmer, J. and Shiu, L.S. (1999), "Coming home? Adjustment of Hong Kong Chinese expatriate business managers assigned to the People's Republic Of China”, International Journal of Intercultural Relations, Vol. 23 No. 3, pp. 447-465.

Shannon-Baker, P. (2015), “But I wanted to appear happy': how using arts-informed and mixed methods approaches complicate qualitatively driven research on culture shock", International Journal of Qualitative Methods, Vol. 14 No. 2, pp. 34-52.

Tahir, A.H.M. and Ismail, M. (2007), "Cross-cultural challenges and adjustments of expatriates: a case study in Malaysia”, Alternatives: Turkish Journal of International Relations, Vol. 6 Nos 3/4, pp. $72-99$.

Visit Saudi (2020), "Saudi”, available at: www.visitsaudi.com/en.

Ward, C. and Rana-Deuba, A. (2000), "Home and host culture influences on sojourner adjustment", International Journal of Intercultural Relations, Vol. 24 No. 3, pp. 291-306.

Waxin, M.F. and Panaccio, A. (2005), "Cross-cultural training to facilitate expatriate adjustment: it works”, Personnel Review, Vol. 34 No. 1, pp. 51-67.

Waxin, M., Roger, A. and Chandon, J. (1997), "L'intégration des expatriés dans leur nouveau poste: une approche contingente et quantitative", GRH Face à la Crise, pp. 324-342.

Zakaria, N. (2000), "The effects of cross-cultural training on the acculturation process of the global workforce", International Journal of Manpower, Vol. 21 No. 6, pp. 492-510.

\section{Corresponding author}

Oscar Dousin can be contacted at: odousin@ums.edu.my

For instructions on how to order reprints of this article, please visit our website: 